\title{
TEATRO, COMUNICACIÓN Y NUEVAS TECNOLOGÍAS
}

\author{
Virginia Guarinos \\ Profesora titular de Narrativa audiovisual y del espectáculo. Universidad de Sevilla.
}

El teatro en pleno siglo XXI ya no es sólo una forma de ocio, es un signo de cultura. En esa eterna polémica entre teatro y cine primero, entre cine y televisión después, la institución teatral ha pasado a convertirse en un tótem cultural, en marchamo de intelectualidad. Pero, independientemente de la verdad o no de este hecho, lo cierto es que la teatralidad, hoy por hoy, excede al mismo teatro y se expande a otras formas de ocio, otros discursos ficcionales o no y otros medios o manifestaciones artísticas. A la irrupción en nuestras vidas cotidianas de las nuevas tecnologías hay que sumar nuestra tendencia cultural occidental a la hibridación de los últimos tiempos. Y de ese modo también el teatro se ha visto afectado, en el buen sentido de la palabra, por dichas nuevas tecnologías y éstas por aquél.

Este número quiere contribuir a otros estudios recientes que tienden lazos entre la Comunicación, el Teatro y las Nuevas Tecnologías, como fruto de una preocupación nueva pero no por ello inexperta. A partir de la década de los 90 del siglo XX comienza a desarrollarse una serie de publicaciones tendentes a reflexionar alrededor de la presencia cada vez más significativa de la tecnología en las prácticas comunicacionales vinculadas con las imágenes visuales, esto ha traído el desarrollo de una serie de ensayos sobre la forma en que se debe 
abordar el lenguaje de las imágenes con la emergencia del paradigma tecnológico. Ya Lyotard ${ }^{1}$ planteaba cómo la postmodernidad presenta lo impresentable y niega la consolidación de la forma bella indagando en nuevas presentaciones. Muy postmoderna es también la tensión entre la inclusión y la exclusión, en nuestro caso de lenguajes y modos expresivos entre el teatro y otros medios. E igualmente la visibilidad, la obscenidad de lo real, el juego de la realidad terminan por construir un mosaico donde la simulación y la apariencia, bases de lo teatral, se vuelven indispensables.

En este sentido hacemos nuestras las palabras de Olivia Fragoso (2007) cuando se refiera a

La importancia del estudio de la imagen pues, se convierte en el sustituto de la realidad, del espacio y del tiempo. Imagen que representa a una cultura obsesionada por mostrar ya no el sentido, el signo o la significación. Hay una modificación y una sustitución de la temporalidad y la espacialidad en una suerte de imágenes repetidas imágenes fractales de la multiplicación a partir del vacío, la interpretación de la imagen le da sentido ya no a una interacción social orientada al desarrollo y crecimiento del hombre sino a una fragmentación de la visión del mundo que lo convierte en exceso de instantaneidad. Un hombre cuyas relaciones están basadas en la anomia, un hombre que se relaciona con otro espectral, vacío, carente de identidad en un espacio inexistente y con una carencia de reglas reguladoras. El tradicional intercambio comunicativo cara a cara se ha trastocado por una forma comunicativa en una cultura de la simulación y de la sustitución que nos hace preguntarnos por el sentido de realidad en este complejo intercambio de representaciones del mundo dadas por simulacros y apariencias en donde la imagen se encarga de gestar una suerte de realidad más allá de lo real, una hiper-realidad obsesionada por el consumo basado en lo maquínico y en el exceso de información, consumo en un espacio virtual que ocasiona que se de un debilitamiento de lo real. El espacio público deja de ser un espacio de identidad colectiva para convertirse en aquel lugar en donde no se es, en donde el personaje se confunde con la escenografía y los diálogos fluyen de altavoces etéreos. Nadie ve, nadie escucha, nadie existe ${ }^{2}$.

Los creadores de imágenes se enfrentan estéticamente a conceptualizar una realidad fragmentándola y compartiendo planteamientos estéticos que antes diferenciaban unas artes de otras de forma identitaria. Ahora la hibridación y la contaminación se expanden de unas artes a otras y, en la mayoría de los casos, los soportes y los medios que las nuevas tecnologías proporcionan tienen buena culpa de ello. Pero no sólo los creadores, también los espectadores,

\footnotetext{
${ }^{1}$ En cualquiera de sus aportaciones: (1989): La condición posmoderna, Madrid, Cátedra, (1996): La posmodernidad, Barcelona, Gedisa; también en trabajos como los de Giani Vattimo (1990): La sociedad transparente, Barcelona, Paidós o Jean Baudrillard (1986): De la seducción, Madrid, Cátedra.

${ }^{2}$ De su artículo “Imagen, simulación y simulacro”, en Razón y palabra, n 59. En línea en http://www.razonypalabra.org.mx/anteriores/n59/varia/ofragoso.html (14/III/2008).
} 
lectores, jugadores, consumidores se han debido aclimatar a los nuevos pactos ficcionales en esta era del “declive del hombre privado” que llama Maldonado (2007:44) ${ }^{3}$.

¿Dónde queda el teatro en todo esto? ¿En locales de teatro, pasacalles, espacios donde se establezca bien diferenciadamente la simulación de la representación y la relación espectatorial quede bien clara...? ¿ ¿Y en las pantallas de los ordenadores, y la teatralidad en los chats, y los personajes entre los avatares...? Decididamente para los que hemos nacido apenas con televisión y hemos asistido a la generalización de ordenadores y videojuegos y consolas con cierta madurez la experiencia es bien distinta a la de los cibernativos, nuestros hijos, nativos digitales o egeneración. Las nuevas formas de relación crean un nuevo imaginario y un nuevo modo de relacionarse donde las jerarquías sociales se quiebran y también las culturales. Las plataformas giratorias y las complejas tramoyas resultan ya ingenuas en comparación con decorados virtuales, experiencias con pantallas, con volúmenes concéntricos, cuando no con personajes espectrales sin cuerpos de actores tangibles ${ }^{4}$, o directamente con emisión teatral por Internet. Este binomio humano-máquina y las oleadas continuas de renovación infotecnológica harán necesaria para nuestras futuras generaciones una renovación de la Teoría del teatro y con ella de la teatralidad. No queda más remedio en tanto que “de tal binomio, si se saben utilizar las capacidades protésicas del segundo y tiene criterio para hacerlo, se amplifica a sí mismo y amplifica sus acciones” (Sáez Vacas: 2007)5 . Y no sólo refiriéndonos al espectáculo teatral en sí

3 Tomás Maldonado (2007): Memoria y conocimiento. Sobre los destinos del saber en la perspectiva digital, Barcelona, Gedisa.

${ }^{4}$ Véanse ejemplos de ello en el artículo de Francisco Díaz-Faes: “Teatro y nuevas tecnologías”, en La ratonera: Revista asturiana de teatro, $\mathrm{n}^{\circ} 12, \quad 2004, \quad$ p.85. Texto completo en línea en http://dialnet.unirioja.es/servlet/articulo?codigo=2245234 (12/II/2008) o en los de Iñigo Sarriugarte (2004): “Interferencias entre el teatro y el performance bajo la tutela de las nuevas tecnologías”, en José Romera (ed.), Teatro, prensa y nuevas tecnologías, Madrid, Visor, pp.465-473 y de Eduardo Vasco en “Las nuevas tecnologías en el teatro”, en $A D E$, Revista de la Asociación de Directores de Escena de España, n85, 2001, pp.233-234. O también en el artículo de María Domínguez Alba (2007): “Artes escénicas y nuevas tecnologías: el teatro virtual”, en Afuera. Revista de crítica cultural, $\quad \mathrm{n}^{\mathrm{O}} \quad 3 . \quad \mathrm{En}$ línea en http://www.revistaafuera.com/pagina.php?seccion=ArtesEscenicas\&page=03.ArtesEscenicas.Alba.ed.htm\&idautor=51 (23/IV/2008).

${ }^{5}$ Fernando Sáez Vacas (2007): “TVIC: Tecnologías para la vida cotidiana”, en Telos, nº 73. En línea en http://www.campusred.net/TELOS/editorial.asp?rev=73 (13/II/2008). 
mismo también al espectador. Ese espectador acostumbrado a la recepción en compañía y en simultaneidad ahora está aclimatándose a la individualización de las prácticas informacionales y culturales derivadas del uso de las tecnologías de la información y comunicación. La propia sociedad favorece el uso de las TIC, como dice Miège (2007):

\begin{abstract}
En un doble sentido: conectando a la vez todo lo que parte de la producción (o de la emisión) hacia el consumo (y la recepción), y actuando de un campo social a otro (como los nuevos productos educativos colgados en la Red, que integran ya elementos propios de las industrias culturales) (...) La comunicación mediatizada distinta de la comunicación ordinaria, e incluso opuesta a ella en aspectos originales y bien diferenciados, parece una perspectiva que debe ser sometida a revisión. A pesar de los temores y reacciones alarmistas siempre dispuestas a alzar la voz, principalmente a propósito del uso de las TIC por los niños o por los hiper-consumidores; y a pesar de las evaluaciones negativas o descalificadoras de ciertos sociólogos, lo que realmente vemos organizarse en este ámbito mantiene los términos de la coexistencia, del funcionamiento paralelo, incluso a veces de la complementariedad. Entre los numerosos síntomas detectables, dos apoyan especialmente esta afirmación: el tiempo que se pasa ante las pantallas informáticas para realizar actividades de orden privado no ha ido en detrimento del consagrado a los intercambios individuales (más bien parece ser la audiencia de las cadenas generalistas de televisión la que parece verse algo afectada); y la enseñanza a distancia, que hasta hace poco se anunciaba como la inminente sucesora de una parte de las instituciones educativas para ocupar una proporción creciente de la oferta de estudios, tiene grandes dificultades para desarrollarse y se limita actualmente a ciertos "compartimentos" que representan sólo una parte débil de la actividad docente, sin peso suficiente para impulsar cambios en la comunicación educativa ${ }^{6}$.
\end{abstract}

Y queremos decir con ello que aunque el teatro "tradicional” (ya el de vanguardia o experimental también es tradicional) no vaya a desaparecer y puedan darse las simultaneidades de formas, formatos y medios, bien merece la pena estar preparados para el futuro. Trabajos importantísimos, como los de Dixon, investigaciones como las del centro dirigido por José Romera, SALITEN@T, (Centro de Investigación en Semiótica literaria, Teatro y Nuevas Tecnologías de la UNED), monografías como las de la revista Signa (nº 17, de marzo de 2008) dedicada a teatro y nuevas tecnologías, experiencias como las de Tecnoescena. Sensibilización

${ }^{6}$ Bernard Miège (2007): “La cuestión de las TIC. Hacia nuevos planteamientos”, en Telos, nº 73 . Versión en línea en http://www.campusred.net/TELOS/articuloAutorInvitado.asp?idarticulo=1\&rev=73 (14/II/2008). En el mismo sentido puede leerse el artículo de Rosalía Winocur (2007): “Nuevas tecnologías y usuarios. La apropiación de las tics en la vida cotidiana”, Telos, $\mathrm{n}^{\circ}$ 73. En línea en http://www.campusred.net/TELOS/articuloexperiencia.asp?idarticulo=1\&rev=73 (14/II/2008). 
en arte y tecnología o Imaginación atrapada o Alternativa teatral (www.tecnoescena.com, www.alternativateatral.com y www.imaginaciónatrapada.com 23/IV/2008) corroboran que esta preocupación se arraiga entre los investigadores y entre los creadores.

El director de Alternativa teatral, (“página donde habitan las tribus teatrales”, según reza en su subtítulo), Javier Acuña, dice en entrevista realizada por Diego Braude (2008):

\begin{abstract}
La mirada apocalíptica está buena, pero... todo es fatalismo, y el mundo siempre está por destruirse, ¿no? Como que el mundo siempre está al borde de la destrucción, y probablemente sea algo real, pero ahí es donde me parece que aparece la reflexión artística. Yo creo que los artistas son verdaderamente los únicos que pueden salvarnos del progreso tecnológico catastrófico, de la visión fatalista. Porque yo creo que no es la única cuestión posible que te plantea la tecnología, que ahí es una cuestión de pura resistencia a lo nuevo, que la gente de teatro lo tiene mucho. Quizás pase algo de esto que la tecnología por ahí pone en crisis algo del concepto teatral, no sé por qué la gente se resiste tanto. Y de hecho, quienes vos ves en teatro que se vinculan con la tecnología, es gente que ya está vinculada, o que por ahí, como los de Monoambiente, terminan accidentalmente por encontrar un recurso que después cuando lo usan empiezan a ver las posibilidades. Pero yo creo que eso está en gestación, y nosotros lo que queremos es participar de esa gestación de cuál es esa identidad artístico-tecnológica, al menos en relación a la escena ${ }^{7}$.
\end{abstract}

Contribuimos a ello con esta monografía de Icono 14. En ella encontrarán una selección de nueve artículos además de una bibliografía comentada sobre teatro, comunicación y nuevas tecnología, realizada por Alberto Hermida; una relación de páginas webs, blogs y sitios relacionados con el teatro en general, el teatro y las nuevas tecnologías y el teatro en Internet, elaborada por Javier Lozano. Igualmente se puede leer una entrevista con el dramaturgo y director del Teatro Lope de Vega de Sevilla, Antonio Álamo, a cargo de Valerio Durán, y un breve texto dramático inédito, Dikadoa, pensado para ser montado escénicamente con nuevas tecnologías, cedido por su autor para esta publicación, el director de escena Alfonso Zurro, a quien agradecemos especialmente esta colaboración.

De los artículos de investigación, hemos procurado ofrecer una variedad que comprenda la relación del teatro con las tecnologías externas a él y las modernas formas de comunicación. Así, encontrarán el artículo de Juan Antonio Ríos Carratalá que tiende el puente tradicional entre el teatro y el cine, centrándose en el caso de Atraco a las tres, como ejemplo de obra de la

${ }^{7}$ Diego Braude (2008): “Entrevista a Javier Acuña”, en Imaginación atrapada, versión en línea en http://www.imaginacionatrapada.com.ar/Teatro/entjavieracuna.htm (23/IV/2008). 
cinematografía clásica española de comedia adaptada para su representación escénica en Atraco a las tres (1962): Actualización cinematográfica y versión teatral. Rafael Cremades, por su parte, se encarga de las relaciones entre teatro y televisión, con una propuesta para el análisis de obras teatrales adaptadas para televisión, bajo el título Análisis de la puesta en imágenes del teledrama. El uso de la tecnología como fijación del texto escénico es la propuesta sobre la que reflexiona Fernando Melgosa en su artículo La documentación audiovisual del espectáculo. Mabel Brizuela escribe sobre la obra Caleidoscopio, de Gustavo Montes donde la tensión entre la pantalla y el escenario se revela en su artículo Entre la imagen y el silencio. La palabra escindida en Caleidoscopio, de Gustavo Montes. Las distancias entre el relato y lo dramático quedan estudiadas en las páginas de Vicente Peña sobre Espacio dramático y espacio narrativo.

La nueva sociedad filtrada por medios y máquinas exige nuevos planteamientos ante el hecho teatral, la obra de teatro, la recepción y la creación. A veces esa sociedad recurre todavía al teatro, a la dramatización sin mecanizar, como medio que cuenta con la imaginación por actores y receptores sin necesidad de más tramoyas tecnologías. A esto refiere el uso de los cuentos dramatizados en la educación sobre los que se habla en el artículo de Julia Iglesia titulado Los cuentos motores como herramienta pedagógica para la educación infantil y primaria. A pesar de ello, los videojuegos, en consolas, en Internet, las nuevas relaciones virtuales conforman nuevos modos de representación que hacen necesaria la reflexión sobre los términos simulación, representación... De ello trata Virginia Guarinos en el artículo ¿Representar o simular? Esa es la pregunta. Los límites de la representación. Otras formas de ocio relacionadas con la espectacularidad pueden llegar a situarse al mismo nivel que la experiencia teatral y ése es el tema sobre el que gira el artículo La hibridación en las nuevas formas dramáticas y espectaculares del siglo XXI, firmado por Inmaculada Gordillo. Y cierra este volumen virtual el trabajo de Valeria Cotaimich sobre ciberteatro con el título Hacia un teatro de cyborgs. Artes escénicas, tecnología/s y subjetividad/es. En este último artículo se encontrará también una relación sobre la actividad teatral y tecnológica en Argentina, país que despunta en estos momentos tanto en práctica como en líneas de investigación sobre el tema, motivo por el cual se incluyen dos firmas de autoras argentinas en esta monografía, las compañeras Mabel Brizuela y Valeria Cotaimich.

El dramaturgo checo Karel Capel escribió la obra R.U.R. (Robots Universales Rossum) en 1921, supuesto inventor de la palabra robot (él inventó el concepto y su hermano Josef le puso 
nombre, esclavo en su lengua) que aparece por primera vez en ella, probablemente no imaginaba que el modelo de mundo de ficcionalidad no verosímil, de ciencia ficción, que plantea esta obra, iba a convertirse casi en realidad efectiva. Lo que en aquel momento eran hombres interpretando a robots, ahora son cyborgs, hologramas, fantasmagorías interpretando a hombres, sustituyendo a actores. Y aún no hemos llegado a 2021, ni siquiera un siglo ha sido necesario. 